\title{
Representaçôes sociais de saúde-doença de conselheiros municipais de saúde
}

| ${ }^{1}$ Luciana Melo de Moura, ${ }^{2}$ Helena Eri Shimizu |

Resumo: O objetivo do estudo foi conhecer a estrutura das representações sociais de saúde e doença dos conselheiros municipais da Região Integrada de Desenvolvimento do Distrito Federal e Entorno, bem como analisar a relação entre essas representações sociais e o papel dos conselheiros de saúde no sistema. Adotou-se a Teoria das Representaçōes Sociais e do Núcleo Central como referencial teórico. Aplicaramse 71 questionários aos conselheiros para verificar seu perfil, além de se empregar a técnica de associação livre e hierarquizada de palavras aos termos indutores "saúde" e "doença", com análise pelo software EVOC. Em relação ao perfil dos conselheiros, $16,9 \%$ são representantes de gestores, $40,8 \%$, de trabalhadores e 42,3\% , de usuários. Os resultados revelam que a representação social de saúde encontra-se associada às ideias de atendimento, qualidade de vida e de vida associada à longevidade. A representação social de doença vincula-se à patologia, objetivada no câncer e na ideia de dor, tristeza, sofrimento em decorrência do adoecimento. É preciso avançar na compreensão do processo saúde-doença, considerando-o como fenômeno psicossocial historicamente construído, que, em razão de sua abrangência e dinamicidade, requer também uma análise pela perspectiva cultural.

> Palavras-chave: saúde; doença; representação social; conselhos de saúde.

\footnotetext{
1 Secretaria de Estado de Saúde do Distrito Federal. Brasília-DF, Brasil (melo310577@gmail.com).

2 Universidade de Brasília, Saúde Coletiva. Brasília-DF, Brasil (helena.eri.shimizu@gmail.com).
} 
A participação da população na gestão da saúde por meio dos conselhos e conferências representa grande avanço na democracia representativa em nosso país e enfrenta como verdadeiro desafio a concretização de suas proposições, entre as quais se destaca a reorientação do modelo de atenção à saúde.

Nesse sentido, os conselhos de saúde (CS) são fundamentais para o aprofundamento da democracia participativa. Contudo, existem diversas dificuldades nesse modelo de gestão, como a cooptação de dirigentes com vistas a atender interesses de grupos sociais específicos, caracterizando o neocorporativismo. Soma-se a isso o fato de os CS se tornarem altamente burocratizados, favorecendo a hierarquia e a legitimação das ações e resoluçōes do gestor (DURÁN; GERSCHMAN, 2014).

Estudos apontam que os CS se transformaram em espaços restritos à aprovação de verbas e de projetos setoriais, ou seja, de legitimação das práticas governamentais, impossibilitando de fato o exercício político deliberativo (PAIVA; VAN STRALEN; COSTA, 2014; SHIMIZU et al., 2013).

A institucionalização dos conselhos, em verdade, acabou por representar o legado de se tornar mais uma estrutura organizativa do próprio Estado. Como consequência, os CS perderam a organicidade com os movimentos sociais que estiveram na luta pela saúde enquanto direito social e universal à cidadania (DURÁN; GERSCHMAN, 2014). Portanto, é preciso resgatar a dinamicidade dos CS com a finalidade de destacar as demandas materiais da população, cuja referência objetiva são as exclusões e carências cotidianas, que devem ser traduzidas em representações simbólicas, essenciais para fortalecer a defesa da saúde (SCHERER-WARREN, 2006).

Ademais, os conselheiros de saúde são considerados sujeitos estratégicos que podem contribuir para o delineamento dos modelos de atenção à saúde, restritos ou abrangentes, bem como influenciar, sobremaneira, as políticas públicas de saúde municipais, revertidas em serviços prestados à comunidade. Dessa feita, as concepções de saúde e de doença abarcadas por esses sujeitos sociais contribuem para conformar suas atitudes e práticas no âmbito dos conselhos.

Contudo, os significados de saúde e de doença modificam-se ao longo da história, determinando modelos e o funcionamento dos sistemas de saúde. Um grande marco da definição de saúde foi elaborado pela Organização Mundial de 
Saúde (OMS), em 1948, quando considerou a saúde como o estado de completo

bem-estar físico, mental e social, e não meramente a ausência de doença e incapacidade. À época, tal conceito trouxe contribuições importantes; todavia, foi bastante criticado, pois, ao considerar a saúde como um estado de bem-estar pleno, incitou a medicalização da sociedade, além de mostrar-se uma concepção impraticável e inatingível (HUBER et al., 2011).

Diversas definições contemporâneas foram propostas. Canguilhem (2009) afirma que a saúde corresponde tanto à dimensão biológica da vida quanto ao modo de vida, ao considerar assimiláveis as dimensōes subjetivas, filosófica, além da doença e dos riscos. Huber et al. (2011) propuseram um conceito reformulado de saúde como sendo a capacidade de adaptação e de autogestão em face dos desafios sociais, físicos e emocionais. Almeida-Filho (2011), por sua vez, afirma que saúde, doença e cuidado são fenômenos que extrapolam o âmbito biológico, pois contêm caráter histórico e político.

Alguns fatores contribuem para modelar a saúde: as determinaçôes sociais, as práticas de saúde, a construção política das instituições de saúde. Esses modelos explicativos do fenômeno saúde-doença, por serem objetos de forte impacto na vida das pessoas, têm a capacidade de se configurar como temas de conversaçóes, como matérias dos meios de comunicação (ALMEIDA; SANTOS, 2011).

As concepções de saúde e doença que circulam pela sociedade por diversos meios de comunicação ao longo dos anos podem ter o potencial para conformar e transformar as representações sociais dos conselheiros de saúde, bem como da própria população (SHIMIZU et al., 2013; SHIMIZU; MOURA, 2015). Isso porque a construção do conhecimento é transversalizada pelo saber instituído, elaborado pela produção científica, e pelo senso comum, baseado na vivência cotidiana (GAZZINELLI et al., 2013). Tais representaçōes podem contribuir para as discussóes e tomadas de decisóes, que podem ter impactos positivos ou negativos nos serviços de saúde (PAIVA; VAN STRALEN; COSTA, 2014).

As representaçôes sociais se originam dos encontros das pessoas nos diferentes espaços onde transitam e se comunicam (MOSCOVICI, 2010). Portanto, as práticas políticas são materiais privilegiados para a investigação dos sistemas culturais e sociais, que contém dimensões individuais e coletivas (JODELET, 2013, 2015). Sua aplicação no campo da pesquisa em saúde tem demonstrado, por vezes, descompassos entre a política e as representações sociais sobre as práticas de saúde (SAÏAS et al., 2014). 
Fica evidente que os conselheiros de saúde produzem conhecimentos específicos e compartilhados entre si, os quais se refletem em suas ações nas arenas de participação social (SHIMIZU et al., 2013; SHIMIZU; MOURA, 2015; PAIVA; VAN STRALEN; COSTA, 2014). Nesses espaços, ocorre também a expressão de demandas e expectativas dos diferentes atores sociais que participam das decisões políticas do setor saúde. Portanto, é fundamental conhecer as representaçôes sociais dos conselheiros de saúde acerca do processo saúde-doença, pois estas podem influenciar as suas práticas políticas cotidianas (SHIMIZU; MOURA, 2015).

O processo saúde-doença na perspectiva hegemônica, definido pelo modelo multicausal, reduz a explicação do aparecimento das doenças aos fatores de risco, bem como atribui aos fatores biológicos o mesmo peso e importância que os sociais (LAURELL; MARQUEZ, 1983). Entretanto, o processo saúde-doença pode ser compreendido de outra maneira: como resultante do processo de produção, enquanto uma formação social totalizante, coordenado por estruturas singulares e dinâmicas (LAURELL; MARQUEZ, 1983).

Para além de modelos conceituais técnico-científicos sobre saúde-doença, verifica-se que o sistema central de uma representação social é composto por elementos arcaicos enraizados na cultura de uma sociedade. Observa-se, também, que a abordagem desse objeto se faz presente tanto a partir do universo reificado quanto do consensual. Logo, apesar dos avanços na concepção do processo saúde-doença, é possível deparar-se com representações baseadas em modelos hegemônicos. Por essa razão, é importante conhecer a estrutura das representaçôes sociais que permite evidenciar tanto os elementos centrais, mais difíceis de serem modificados, quanto os elementos periféricos, mais flexíveis e permeáveis às mudanças, a fim de compreender as informações, posicionamentos e justificativas das ações dos conselheiros. Estudos apontam para a (re)apropriação feita por estes em relação a categorias explicativas da saúde e da doença, em um processo de ressignificação que coloca em pauta categorias populares e eruditas, científicas e do senso comum, simultaneamente (SHIMIZU et al., 2015; SANTOS et al., 2014; BRASIL; COSTA; JORGE, 2012).

Este estudo teve como objetivo conhecer a estrutura das representações sociais de saúde e de doença dos conselheiros de saúde de municípios da Região Integrada de Desenvolvimento do Distrito Federal e Entorno (Ride-DF), 
bem como analisar a relação entre essas representações sociais e o papel dos conselheiros de saúde no sistema.

\section{Método}

Trata-se de estudo descritivo, fundamentado na Teoria das Representações Sociais, de Serge Moscovici (2010), em que se adotou a proposta complementar da Teoria do Núcleo Central, de Jean-Claude Abric (1998). Esta última propõe que uma representação social é organizada em torno de um núcleo central, formado por um ou mais elementos que dão significado à representação e que por isso são estáveis e definem a homogeneidade de um grupo. Em torno desse elemento central, ou desses elementos centrais, organizar-se-iam os elementos periféricos, considerados o aspecto móvel e evolutivo da representação, e que teriam como função a concretização, a regulação e a defesa do núcleo central (ABRIC, 1998).

A abordagem estrutural das representaçôes sociais aparece como um elemento importante para a identificação dos termos e expressōes que mais definem e organizam as representações de saúde e doença, auxiliando a análise do campo comum e, porque não dizer, das crenças compartilhadas pelos conselheiros municipais de saúde. Para tanto, o estudo foi realizado nos conselhos municipais de saúde instituídos em oito municípios da Ride-DF. A Ride-DF é formada por municípios dos estados de Goiás e Minas Gerais localizados ao redor do Distrito Federal (DF) e foi criada por força da Lei Complementar no 94, de 19 de fevereiro de 1998, regulamentada pelo Decreto $\mathrm{n}^{\circ} \mathbf{7 . 4 6 9}$, de maio de 2011 (BRASIL, 2011), com vistas ao aprimoramento e ampliação dos serviços públicos essenciais, à promoção de atividades econômicas na região e à superação das dificuldades vivenciadas por sua população, como a pouca oferta de serviços de saúde (PIRES et al., 2010).

É importante destacar que os municípios da Ride-DF são considerados cidades dormitórios: possuem significativo contingente populacional que, em decorrência da especulação imobiliária no território do DF, teve de migrar para cidades adjacentes. Em todos os municípios da Ride-DF, prevalece forte dependência do DF pelos serviços públicos de saúde. Somam-se a isso o baixo rendimento médio da maioria da população e a elevada taxa de informalidade no mercado de trabalho, em que mais de $80 \%$ da população não têm plano de saúde privado (CODEPLAN, 2013). Assim, o acesso aos serviços públicos de saúde é 
quase universal, alcançando $94,14 \%$ da população local. Desse total de usuários, 66,10\% utilizam serviços de saúde no próprio município, enquanto 33,68\% dão preferência a uso dos equipamentos do DF (CODEPLAN, 2013). Uma parcela ínfima $(0,27 \%)$ utiliza os serviços ofertados em Goiânia, Anápolis ou outros locais (CODEPLAN, 2013). No que tange à escolaridade da população, sobressaem dois níveis com maior número de pessoas: principalmente ensino fundamental incompleto, predizendo um baixo nível de escolaridade, seguido do ensino médio completo.

Nessa direção, foram selecionados os municípios da Ride-DF com população acima de 50 mil habitantes e que realizaram conferências municipais de saúde a cada dois anos. Dessa forma, participaram do estudo os conselhos das regiōes do Entorno Sul (Cidade Ocidental, Novo Gama, Santo Antônio do Descoberto e Valparaíso, todas do estado de Goiás), do Entorno Norte (Formosa e Planaltina, ambos municípios goianos) e das regiōes de Pirineus (Pirenópolis - GO) e Unaí (Buritis - MG).

Foram acompanhadas 21 reuniōes ordinárias e extraordinárias dos conselhos municipais de saúde selecionados, no período de junho a dezembro de 2012, ocasião em que foram aplicados os questionários de evocação aos conselheiros de saúde presentes nas reuniōes, pela mesma pesquisadora. Portanto, tratou-se de amostra intencional de conselheiros, cujos critérios de inclusão foram: mínimo de seis meses de mandato e participação regular nas reuniōes. Foram excluídos os conselheiros com menos de seis meses de mandato, ausentes nas reuniōes ou que se negaram a participar. Portanto, participaram da pesquisa 71 sujeitos, dos quais 30 foram representantes de usuários, 29 representantes de trabalhadores e 12 representantes de gestores/prestadores.

A coleta de dados baseou-se no emprego de questionário semiestruturado e autoadministrado dividido em três partes. A primeira parte foi composta por variáveis descritivas: idade, sexo, segmento, situação trabalhista, número de mandatos no conselho, grau de escolaridade e uso de plano de saúde ou do Sistema Único de Saúde (SUS). A segunda utilizou a técnica de evocação livre para que os conselheiros citassem seis palavras ou expressōes que lhes ocorressem imediatamente em relação aos termos indutores "saúde" e "doença" (ABRIC, 1993; SÁ, 1996). A terceira parte empregou a técnica de hierarquização de itens para que os conselheiros enumerassem em ordem de importância as três palavras ou expressōes consideradas mais importantes (ABRIC, 1993; SÁ, 1996). 
Os dados coletados na primeira parte do questionário foram sistematizados no Microsoft Excel 2010, e com o auxílio do programa SPSS (Statistical Package for the Social Sciences), versão 17.0, foi realizada a análise univariada com a construção da distribuição de frequências.

As respostas coletadas na segunda parte do questionário foram submetidas à análise de evocação, por meio do software EVOC (Ensemble de Programmes Permettant l'Analyse des Évocations), versão 2000. Este permite identificar, além do conteúdo das representações, sua organização interna em função de um duplo critério: frequência (freq.) versus ordem média de evocação (OME). Quanto mais próxima a média estiver de 1 , maior o grau de importância das palavras indicadas. De acordo com o pressuposto da perspectiva estrutural das representações sociais de Abric (1998), a associação desses dois critérios distribuídos em quatro quadrantes permite revelar os prováveis elementos centrais e periféricos de uma representação social. As palavras com uma alta frequência, e às quais os sujeitos atribuem importância na definição do objeto, expressam sentido central e organizador da representação social. As análises com o software EVOC sobre as palavras/expressōes evocadas a partir dos termos indutores "saúde" e "doença" foram efetuadas separadamente.

Os dados contidos na terceira parte do questionário foram submetidos ao teste de centralidade. Nessa etapa, foi realizada a análise das palavras ou expressões evocadas após a enumeração em ordem de importância no programa EVOC, em que sua organização interna se deu em frequência versus ordem média de importância (OMI) para assim proceder à comparação com a ordem de evocação livre.

Este estudo foi aprovado pelo Comitê de Ética da Fundação de Ensino e Pesquisa do Distrito Federal com o número de parecer 001/2012. Todos os participantes de pesquisa foram voluntários e assinaram termo de consentimento livre e esclarecido.

\section{Resultados}

Em relação ao perfil dos conselheiros, os resultados (tabela 1) evidenciaram que têm em média 40 anos de idade e 53,5\% são do sexo feminino. Quanto ao segmento que representam nos conselhos municipais de saúde, $16,9 \%$ são representantes de gestores, 40,8\%, de trabalhadores e 42,3\%, de usuários. A 
maioria dos conselheiros da amostra é servidor público, 56,3\%. Estão no primeiro mandato $59,0 \%$ dos conselheiros. Em relação ao grau de escolaridade, $52,2 \%$ têm ensino médio e 39,4\% ensino superior. $69 \%$ não possuem plano de saúde. Outro dado interessante diz respeito ao uso do SUS: 94,4\% afirmaram usá-lo. Entre os conselheiros que usam o SUS, 74,7\% o fazem frequentemente, enquanto $25,3 \%$ o fazem raramente.

Tabela 1. Características sociodemográficas dos conselheiros municipais de saúde de oito municípios da RIDE-DF. Brasília, 2012

\begin{tabular}{|c|c|c|}
\hline Variáveis & Frequência & Porcentagem \\
\hline \multicolumn{3}{|l|}{ Segmento } \\
\hline Gestor & 12 & 16,9 \\
\hline Trabalhador & 29 & 40,8 \\
\hline Usuário & 30 & 42,3 \\
\hline Total & 71 & 100 \\
\hline \multicolumn{3}{|l|}{ Sexo } \\
\hline Masculino & 33 & 46,5 \\
\hline Feminino & 38 & 53,5 \\
\hline Total & 71 & 100 \\
\hline \multicolumn{3}{|l|}{ Situação Trabalhista } \\
\hline Empregado com carteira & 3 & 4,2 \\
\hline Empregado sem carteira & 6 & 8,5 \\
\hline Servidor público & 40 & 56,3 \\
\hline Aposentado/Pensionista & 5 & 7,0 \\
\hline Trabalhador Autônomo & 6 & 8,5 \\
\hline Empresário & 5 & 7,0 \\
\hline Desempregado & 6 & 8,5 \\
\hline Total & 71 & 100 \\
\hline
\end{tabular}




\begin{tabular}{|c|c|c|}
\hline Variáveis & Frequência & Porcentagem \\
\hline \multicolumn{3}{|l|}{ Mandato no CMS } \\
\hline 1 mandato & 42 & 59,2 \\
\hline 2 mandatos & 15 & 21,1 \\
\hline 3 mandatos & 10 & 14,1 \\
\hline 4 mandatos & 2 & 2,8 \\
\hline 5 mandatos & 2 & 2,8 \\
\hline Total & 71 & 100 \\
\hline \multicolumn{3}{|c|}{ Grau de escolaridade } \\
\hline $1^{\circ}$ grau incompleto & 4 & 5,6 \\
\hline $2^{\circ}$ grau incompleto & 2 & 2,8 \\
\hline $2^{\circ}$ grau completo & 37 & 52,2 \\
\hline Superior completo & 28 & 39,4 \\
\hline Total & 71 & 100 \\
\hline \multicolumn{3}{|l|}{ Renda mensal } \\
\hline$<1 \mathrm{SM}$ & 2 & 2,8 \\
\hline$\Rightarrow>1<2 \mathrm{SM}$ & 22 & 31 \\
\hline$=>2<3 \mathrm{SM}$ & 11 & 15,5 \\
\hline$=>3<4 \mathrm{SM}$ & 6 & 8,5 \\
\hline$=>4<5 \mathrm{SM}$ & 9 & 12,7 \\
\hline$=>5 \mathrm{SM}$ & 21 & 29,6 \\
\hline Total & 71 & 100 \\
\hline \multicolumn{3}{|l|}{ Plano de Saúde } \\
\hline Tem & 22 & 31 \\
\hline Não tem & 49 & 69 \\
\hline Total & 71 & 100 \\
\hline \multicolumn{3}{|l|}{ SUS } \\
\hline Usa & 67 & 94,4 \\
\hline Não usa & 4 & 5,6 \\
\hline Total & 71 & 100 \\
\hline
\end{tabular}




\begin{tabular}{lcc}
\hline Variáveis & Frequência & Porcentagem \\
\hline Frequência de uso do SUS & 17 & \\
Sempre & 33 & 23,9 \\
Frequentemente & 2 & 46,5 \\
Às vezes & 15 & 2,8 \\
Raramente & 67 & 21,1 \\
\hline Total & & 100 \\
\hline
\end{tabular}

A segunda parte do questionário de evocação revela os achados sobre a estrutura da representação social dos conselheiros municipais de saúde sobre os termos "saúde" e "doença". Os resultados estão apresentados nas tabelas 2 e 4, organizados em tabela de quatro casas. O quadrante superior à esquerda é denominado núcleo central e corresponde à parte mais estável e permanente em uma representação, conferindo-lhe sentido. O quadrante inferior à esquerda denomina-se zona de contraste, na qual pode ser percebido um subgrupo representacional, o que significa dizer que pode demonstrar grupos que pensam de modo diferente da maioria. Os dois quadrantes à direita são a primeira periferia (superior) e a segunda (inferior), que expressam o contexto imediato que as pessoas vivem, o seu contato com a realidade.

Em relação aos elementos centrais da saúde (tabela 2), a ideia de atendimento associa-se a bem-estar, qualidade de vida, vida. Ou seja, o acesso ao atendimento tem como consequências uma melhor qualidade de vida. No segundo quadrante, estão os termos que provavelmente fazem parte do sistema periférico mais próximo do núcleo central, em que a saúde relaciona-se à alimentação e a prevenção. No terceiro quadrante, ou zona de contraste, aparece um subgrupo representacional constituído pelos termos "ausência de doença" e "bem-estar físico e social", bem como por outras palavras que compõem o cuidado em saúde. No sistema periférico mais distante, a saúde relaciona-se à atenção básica, à acessibilidade e à palavra "amor". Aparecem ainda outros elementos que visam garantir a manutenção da saúde e seu restabelecimento, além de elementos que influenciariam o provimento e a qualidade dos serviços de saúde, como a fiscalização e a capacitação. 
Tabela 2. Estrutura da representação social dos conselheiros municipais de saúde de oito municípios da RIDE-DF sobre o termo "saúde". Brasília, 2015

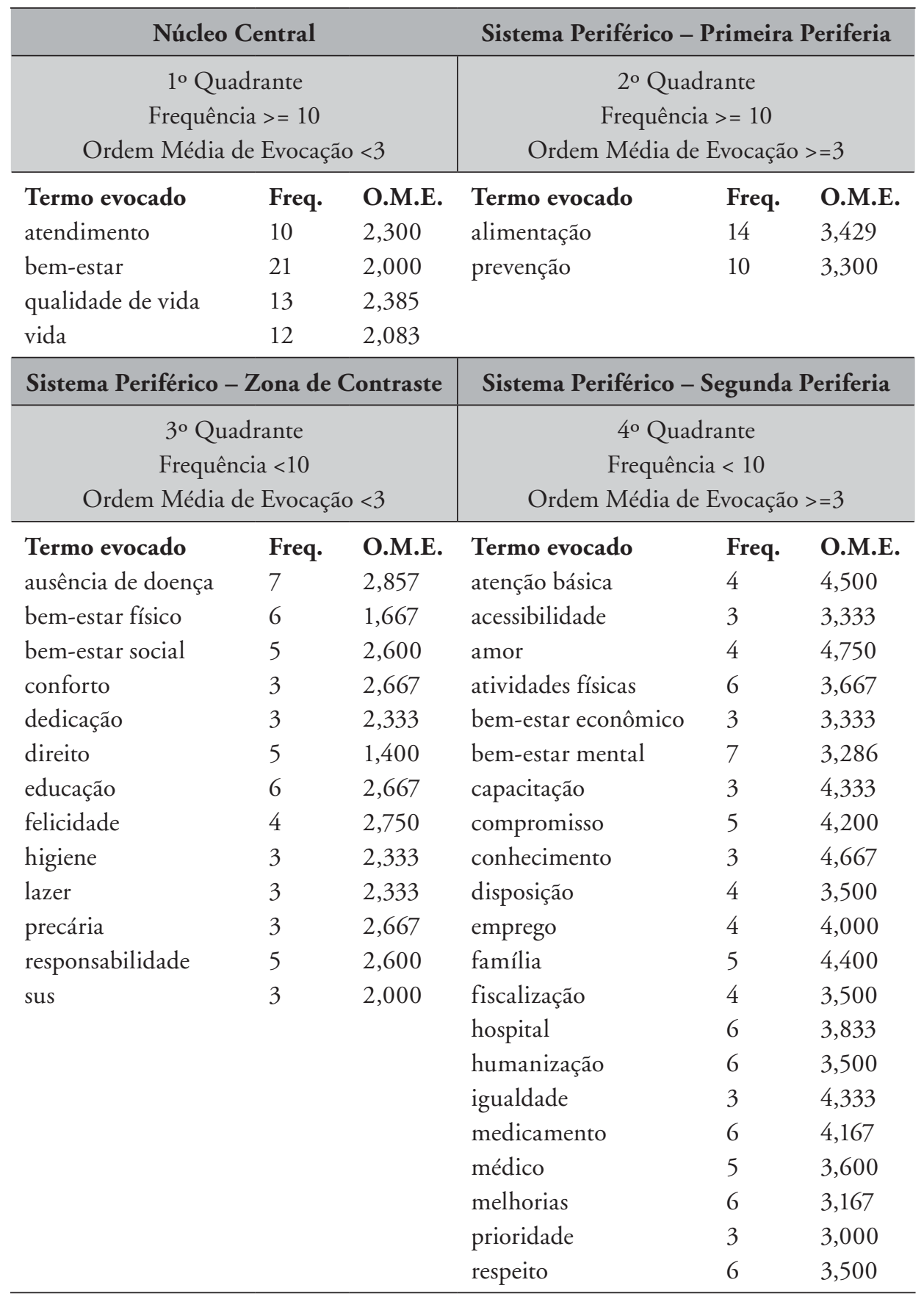


A partir do teste de centralidade (tabela 3), observa-se que, em relação ao termo "saúde", os elementos identificados na análise de evocação se mantêm na análise da ordem de importância.

\section{Tabela 3. Teste de centralidade do termo "saúde". Brasília, 2015}

\begin{tabular}{c|lcc|lcc}
\hline \multicolumn{5}{c}{ Evocação } & \multicolumn{3}{c}{ Importância } \\
\hline \multirow{4}{*}{ Termo evocado } & Freq. & O.M.E. & Termo evocado & Freq. & O.M.E. \\
\hline \multirow{3}{*}{ NC } & atendimento & 9 & 2,300 & atendimento & 10 & 2,500 \\
& bem-estar & 6 & 2,000 & bem-estar & 21 & 2,667 \\
& qualidade de vida & 12 & 2,385 & qualidade de vida & 13 & 2,692 \\
& vida & 6 & 2,083 & vida & 12 & 1,750 \\
\hline \multirow{3}{*}{ SP } & alimentação & 14 & 3,429 & alimentação & 14 & 3,286 \\
& prevenção & 10 & 3,300 & prevenção & 10 & 3,200 \\
\hline
\end{tabular}

Verificou-se que estão presentes no núcleo central das representações de doença dos conselheiros (tabela 4) as patologias crônicas objetivadas no câncer e no diabetes, associadas à ideia de dor, mal-estar, sofrimento, tristeza - sensaçooes que surgem em decorrência da vivência do adoecimento - e, por fim, o tratamento para reverter o quadro patológico. No segundo quadrante, estão os termos que possivelmente fazem parte do sistema periférico mais próximo do núcleo central, em que a doença relaciona-se à depressão e à morte como desdobramentos do adoecimento. No terceiro quadrante, ou zona de contraste, aparece um subgrupo representacional que mantém a ideia de patologia representada na Aids, na dengue, na hipertensão, na doença mental, em que o atendimento pode levar à cura e a doença remete a algo ruim. O elemento "má alimentação" surge como um dos condicionantes do adoecimento. No sistema periférico mais distante, a doença relaciona-se à atenção básica e à geração de angústia, ansiedade, fraqueza e incapacidade. Aparecem ainda outros elementos condicionantes do adoecimento, como a falta de higiene, a falta de saneamento, o estresse e a infecção, além de elementos que influenciariam o provimento e a qualidade dos serviços de saúde, como hospital, medicamento, médico e prevenção. 
Tabela 4. Estrutura da representação social dos conselheiros municipais de saúde de oito municípios da RIDE-DF sobre o termo "doença". Brasília, 2015

\begin{tabular}{|c|c|c|c|c|c|}
\hline \multicolumn{3}{|c|}{ Núcleo Central } & \multicolumn{3}{|c|}{ Sistema Periférico - Primeira Periferia } \\
\hline \multicolumn{3}{|c|}{$\begin{array}{c}\text { 1० Quadrante } \\
\text { Frequência }>=6 \\
\text { Ordem Média de Evocação }<3\end{array}$} & \multicolumn{3}{|c|}{$\begin{array}{c}\text { 2० Quadrante } \\
\text { Frequência >= } 6 \\
\text { Ordem Média de Evocação >=3 }\end{array}$} \\
\hline Termo evocado & Freq. & O.M.E. & Termo evocado & Freq. & O.M.E. \\
\hline câncer & 9 & 1,889 & depressão & 7 & 3,143 \\
\hline diabetes & 6 & 2,500 & morte & 10 & 3,400 \\
\hline dor & 12 & 2,000 & & & \\
\hline mal-estar & 6 & 2,667 & & & \\
\hline sofrimento & 6 & 2,667 & & & \\
\hline tratamento & 5 & 1,875 & & & \\
\hline tristeza & 10 & 2,800 & & & \\
\hline \multicolumn{3}{|c|}{ Sistema Periférico - Zona de Contraste } & \multicolumn{3}{|c|}{ Sistema Periférico - Segunda Periferia } \\
\hline \multirow{3}{*}{\multicolumn{3}{|c|}{$\begin{array}{c}\text { 3० Quadrante } \\
\text { Frequência }<6 \\
\text { Ordem Média de Evocação }<3\end{array}$}} & \multirow{3}{*}{\multicolumn{3}{|c|}{$\begin{array}{c}4^{\circ} \text { Quadrante } \\
\text { Frequência }<6 \\
\text { Ordem Média de Evocação >=3 }\end{array}$}} \\
\hline & & & & & \\
\hline & & & & & \\
\hline Termo evocado & Freq. & O.M.E. & Termo evocado & Freq. & O.M.E. \\
\hline aids & 5 & 2,800 & atenção básica & 3 & 4,000 \\
\hline atendimento & 3 & 1,667 & angústia & 3 & 3,333 \\
\hline ausência de saúde & 3 & 1,667 & ansiedade & 3 & 4,667 \\
\hline cura & 4 & 2,500 & AVC & 3 & 3,667 \\
\hline dengue & 4 & 2,000 & estresse & 3 & 3,000 \\
\hline hipertensão & 5 & 2,800 & falta de higiene & 4 & 3,500 \\
\hline má alimentação & 4 & 2,500 & falta de saneamento & 3 & 3,333 \\
\hline mental & 3 & 1,333 & fraqueza & 3 & 5,000 \\
\hline \multirow[t]{6}{*}{ ruim } & 4 & 1,500 & hospital & 5 & 3,600 \\
\hline & & & incapacidade & 3 & 5,333 \\
\hline & & & infecções & 3 & 4,000 \\
\hline & & & medicamento & 5 & 3,800 \\
\hline & & & médico & 3 & 5,000 \\
\hline & & & prevenção & 3 & 5,000 \\
\hline
\end{tabular}


A tabela 5 demonstra o teste de centralidade do termo "doença". Nele os elementos "câncer", "dor" e "tristeza" permanecem centrais nas análises de evocação e importância.

\section{Tabela 5. Teste de centralidade do termo "doença". Brasília, 2015}

\begin{tabular}{|c|c|c|c|c|c|c|}
\hline & \multicolumn{3}{|c|}{ Evocação } & \multicolumn{3}{|c|}{ Importância } \\
\hline & Termo evocado & Freq. & O.M.E. & Termo evocado & Freq. & O.M.E. \\
\hline \multirow{7}{*}{ NC } & câncer & 9 & 1,889 & câncer & 9 & 1,889 \\
\hline & diabetes & 6 & 2,500 & dor & 12 & 2,250 \\
\hline & dor & 12 & 2,000 & tristeza & 10 & 2,900 \\
\hline & mal-estar & 6 & 2,667 & & & \\
\hline & sofrimento & 6 & 2,667 & & & \\
\hline & tratamento & 8 & 1,875 & & & \\
\hline & tristeza & 10 & 2,800 & & & \\
\hline \multirow{6}{*}{ SP } & depressão & 7 & 3,429 & depressão & 7 & 3,000 \\
\hline & morte & 10 & 3,300 & diabetes & 6 & 3,500 \\
\hline & & & & mal-estar & 6 & 3,333 \\
\hline & & & & morte & 10 & 3,700 \\
\hline & & & & sofrimento & 6 & 3,500 \\
\hline & & & & tratamento & 8 & 3,125 \\
\hline
\end{tabular}

A partir dos testes de centralidade, é possível notar que os elementos parecem compor o núcleo central das representações sociais acerca da saúde e da doença.

\section{Discussão}

Quanto ao perfil dos conselheiros municipais de saúde participantes do estudo, verificou-se boa participação das mulheres, com razoável grau de escolaridade. Além disso, boa parte são servidores públicos. A maioria não possui plano de saúde privado e é usuária regular do SUS, o que pode ser considerado positivo para vocalizar as necessidades de saúde da população da Ride-DF.

O termo "atendimento", presente no núcleo central das representaçôes sociais de saúde, tem sua importância no mundo semântico dos conselheiros justificada pela histórica relação estabelecida entre população e serviços de saúde, sobretudo pela demanda por garantia de acesso a atendimento (CAMPOS, 2014). 
Entretanto, a garantia desse atendimento, bem como o acesso ao tratamento, tem revelado a tradicional influência do modelo biomédico na produção das ações e serviços em saúde pública (PAIVA; VAN STRALEN; COSTA, 2014; GOMES; OLIVEIRA; SÁ, 2011). Nesse sentido, vê-se que os conselheiros reproduzem nas suas representaçōes sociais o discurso médico tradicional atrelado à necessidade de ofertar ações e serviços relacionados ao tratamento das doenças, que tem sido a forma de organização da atenção à saúde historicamente prevalente no sistema de saúde.

Compõem o campo representacional dos conselheiros, mais precisamente no sistema periférico, a atenção básica e a acessibilidade; isso porque houve, nos últimos anos, importante expansão da Estratégia Saúde da Família (ESF). Entretanto, sabe-se que a acessibilidade continua sendo problemática, especialmente se considerarmos as desigualdades regionais. A acessibilidade representa um importante componente do sistema, pois possibilita a chegada dos usuários aos serviços de saúde. Fatores ligados à acessibilidade sócio-organizacional (tempo de espera para a marcação de consulta e para o atendimento, facilidade na realização de exames e aquisição de medicamentos) e geográfica (distância entre a casa do usuário e local de prestação do serviço) são considerados atributos essenciais para a garantia da qualidade na atenção básica, mas ainda precisam ser aprimorados (MENDES et al., 2012).

Observou-se também que a saúde é representada pelos conselheiros como ausência de doença, acompanhada de sentimentos de bem-estar físico e social. Essas representações estão ancoradas no conceito de saúde proposto pela OMS em 1948, que perdurou muito tempo. É preocupante que tanto conselheiros como profissionais de saúde, apesar de terem informação sobre o conceito ampliado de saúde, ainda a percebam como o oposto de doença, podendo trabalhar com esse enfoque nas suas práticas (CÂMARA et al., 2012). Ou seja, reforçar no seu cotidiano ações voltadas para o modelo clínico individual em detrimento do modelo que privilegia a promoção da saúde coletiva.

Constatou-se também que a "qualidade de vida" também faz parte do núcleo central, o que demonstra avanço nas representaçôes sociais de saúde dos conselheiros. Percebe-se que os termos "bem-estar" e "qualidade de vida" encontram ancoragem na Declaração de Direitos Humanos, que trata do direito ao bem-estar e à qualidade de vida, que foram legitimados pela Constituição Federal de 1988. 
Há que se ressaltar que o termo "qualidade de vida" se apresenta polissêmico e admite diferentes formas de abordagens, que refletem conhecimentos, experiências e valores de indivíduos e coletividades que se reportam em variadas épocas, espaços e histórias, resultados de uma construção social com a marca da relatividade cultural (MINAYO, 2013).

Uma forma de perceber a qualidade de vida, mais restrita, que foi encontrada no núcleo central das representações sociais dos conselheiros, centra-se na compreensão de o ser humano viver sem doenças ou com capacidade para superar as dificuldades dos estados ou condiçōes de morbidade (MINAYO, 2013). Outra forma de compreensão da qualidade de vida se expressa em perspectiva ampla, em sua relação com a compreensão das necessidades humanas fundamentais, materiais e espirituais e com a incorporação da perspectiva da promoção da saúde (MINAYO, 2013).

Outro estudo sobre representações sociais masculinas de saúde e doença também mostrou resultados semelhantes: a qualidade de vida como condição necessária para obtenção de saúde, bem como a compreensão de saúde holística, ao se considerar as dimensões físicas, psíquicas, espirituais e sociais, além da necessidade de condições de trabalho, família, alimentação e da sensação de bem-estar (ALMEIDA; SANTOS, 2011).

As representações sociais de qualidade de vida dos conselheiros demonstram ser bastante positivas, e amplas; portanto, com potencialidades para influir nas suas práticas cotidianas no âmbito dos conselhos de saúde, uma vez que as representações sociais agregam as experiências individuais e coletivas.

Ademais, depreende-se que a palavra "vida", presente no núcleo central das representaçôes de saúde, possa estar relacionada à longevidade, haja vista que a evolução tecnológica em saúde e a queda nos índices de mortalidade geraram uma compreensão de saúde vinculada ao aumento da expectativa de vida (GOMES; OLIVEIRA; SÁ, 2011).

A alimentação parece compor o sistema periférico mais próximo do núcleo central das representações sociais de saúde, possivelmente porque a questão da segurança alimentar e nutricional esteve em voga, desde o final da década de 1980, por meio de campanhas que enfatizavam a necessidade de políticas para eliminar a miséria e a fome de milhões de brasileiros. Essa problemática ganhou mais espaço nas políticas públicas e na mídia após o ano 2000, com 
a criação do programa Fome Zero, que teve repercussões positivas, mas ainda requer atenção, sobretudo em relação à qualidade da alimentação (VIEIRA et al., 2013). Portanto, é de extrema relevância que os conselheiros expressem em suas representações a preocupação com a garantia do acesso à alimentação, pois se trata de um direito básico fundamental conquistado no país recentemente. Contudo, parte significativa da população convive com a falta de qualidade alimentar em virtude da precariedade das condições de vida.

Observou-se neste estudo que a palavra "prevenção" está presente no sistema periférico mais próximo das representações dos conselheiros, em detrimento da promoção da saúde. Esse resultado sugere que está mais fortemente presente nas representações dos conselheiros a concepção de processo saúde-doença definido pelo modelo multicausal, que reduz a explicação do aparecimento das doenças aos fatores de risco.

Essa concepção tende a culpabilizar as pessoas que não conseguem alcançar a saúde, por considerar o cuidado da saúde responsabilidade individual (PAIVA; VAN STRALEN; COSTA, 2014). Assim, descontextualiza as questōes oriundas das determinações sociais, tais como a estrutura social, a posição socioeconômica, o aspecto cultural, fatores ambientais, familiares, como preditores da saúde e do bem-estar. Muitos são os determinantes de saúde além do controle individual, o que enseja o debate em torno da saúde enquanto responsabilidade social (AHOLA-LAUNONEN, 2015).

As doenças crônicas compõem o núcleo central das representações em razão do processo de transição epidemiológica que vem ocorrendo de maneira rápida no Brasil. Além disso, constituem problema de saúde de maior magnitude no Brasil e em outros países (SCHMIDT et al., 2011). Dentre elas, o diabetes também tem aumentado substancialmente no Brasil, principalmente em decorrência de mudanças no estilo de vida, que têm causado aumento da obesidade e de outras doenças. A adoção de medidas preventivas surge como possibilidade para controle ou eliminação da doença, o que tem sido reforçado por meio de programas que visam à redução da enfermidade (CAMPOLINA et al., 2013).

O câncer, uma enfermidade que causa grande impacto individual e social, por ser visto como doença de difícil tratamento e até mesmo como sinônimo de morte certa, firma-se no imaginário coletivo, contribuindo para a formação de representações. Esse fato é reforçado pelos conceitos, símbolos e estruturas 
interiorizadas na interpretação de fenômenos orgânicos, amplamente veiculados pelas mídias na contemporaneidade (CÂMARA et al., 2012).

A depressão, considerada a doença do século, aparece nas representações sociais de doença dos conselheiros porque acomete parcela significativa da população e causa grande sofrimento (WHO, 2008). Os diversos sistemas de saúde têm tido gastos consideráveis com o tratamento da doença, mas continuam com dificuldades, pois se observa que a depressão requer profissionais da saúde preparados para compreendê-la em seus múltiplos determinantes (WHO, 2008).

Observa-se que compõem o conteúdo das representações de doença dos conselheiros as enfermidades prevalentes na atualidade, associadas a outros sentimentos negativos delas decorrentes. Resultados similares são encontrados em outros estudos sobre representação social de doença, como o medo da dor, do sofrimento, do abandono, da perda e do medo da morte (ALMEIDA; SANTOS, 2011). A doença exige que o sistema de saúde esteja preparado para dar respostas adequadas à população, sobretudo por meio do atendimento adequado e oportuno, como foi vocalizado pelos conselheiros.

Verificou-se que coexistem nas representações dos conselheiros elementos que demonstram avanços e elementos mais restritivos acerca da compreensão do processo saúde-doença. Nessa perspectiva, Almeida-Filho (2013) propóe um conceito unificado de saúde-doença, para integração, conversão e fusão de vários conceitos e modelos teóricos de saúde-doença, com o propósito de abarcar a complexidade e as múltiplas dimensões desse fenômeno. Tem o intuito não de limitá-lo à causalidade dos processos patológicos, mas de considerar os processos de promoção, proteção, manutenção, recuperação da saúde individual e coletiva, bem como valorizar o contexto socioeconômico, político, histórico, cultural.

As representações sociais de saúde e doença dos conselheiros sinalizam uma tendência à ampliação do seu significado, mas ainda com alguma influência do modelo funcionalista de saúde, o que provavelmente justifica as práticas no interior dos conselhos (SHIMIZU et al., 2013) permeadas por limitações no poder de decisão, práticas hierarquizadas e burocratizadas, ancoradas em modelos de gestão centralizadora. Em realidade, estudos têm mostrado que os conselheiros encontram-se distanciados do seu objeto principal de atuação, a defesa da atenção à saúde de qualidade para a população, devido ao grande envolvimento com práticas burocratizadas no interior dos conselhos (SHIMIZU et al., 2013; SHIMIZU, MOURA, 2015). 
É preciso resgatar o real papel dos conselheiros, ou seja, da defesa da saúde da população, numa perspectiva mais abrangente, não apenas a reivindicação pontual por atendimento hospitalar como comumente têm realizado (SHIMIZU, 2013), mas pela qualidade de vida da população, que requer investimentos na mudança do modelo de atenção à saúde, que, apesar dos avanços nas políticas de saúde, ainda não foi alcançada.

Em suma, apesar das limitações metodológicas, que não permitem generalizações dos resultados, as representações sociais dos conselheiros evidenciam que é preciso avançar na compreensão do processo saúde-doença, considerando-a um fenômeno psicossocial historicamente construído que, em razão da sua abrangência e dinamicidade, requer também uma perspectiva cultural.

\section{Conclusões}

As representações sociais de saúde e doença dos conselheiros municipais de saúde trazem em seu campo representacional, mais especificamente no núcleo central, elementos com tendência à ampliação do significado do processo saúde-doença, objetivada na ideia de qualidade de vida e vida. Todavia, percebem-se também no núcleo central elementos que indicam a influência do modelo funcionalista de saúde - que reduz a compreensão desta ao desequilíbrio orgânico e não considera os determinantes sociais e as dimensões psicossociais - e a reivindicação por atendimento, ou seja, por cuidado das doenças.

Além disso, a existência de elementos condicionantes e determinantes da saúde, tais como a alimentação, educação, emprego, lazer e do adoecimento, como falta de saneamento, localizados no sistema periférico, reforça as transformações na ampliação do significado desse processo. Dado que tais elementos realizam a conexão do sistema central com a realidade cotidiana, pois são elas que dão mobilidade e flexibilidade às representaçōes sociais, regulando e adaptando o núcleo central às necessidades individuais e coletivas.

Há que se reconhecer que o processo de mudança das representações sociais é um movimento lento, pois primeiro são transformados os elementos periféricos da representação social, para depois serem modificados os elementos centrais. Isso sinaliza que as representações sociais de saúde e doença do grupo estudado, que reivindica por acesso e acessibilidade na atenção básica, podem contribuir 
positivamente para a mudança do modelo de atenção. Todavia, elas servem apenas como ponto de partida para responsabilidades individuais e grupais na intervenção e determinação de ações e políticas de saúde.

É preciso incorporar à democracia participativa uma função educativa, inclusive dos conselheiros e, por que não dizer, da população geral acerca das mudanças necessárias na forma de compreender o processo saúde-doença e que subsidiem transformações no modelo de atenção à saúde. Com a possibilidade de participação ativa, os conselheiros podem modificar suas representações e ampliar seus horizontes para além de seus interesses pessoais, ou seja, em defesa de um bem público maior: a defesa do SUS. ${ }^{1}$

\section{Referências}

ABRIC, J. C. Central system, peripheral system: their functions and roles in the dynamic of social representations. Papers on Social Representations, Austria, v. 2, n. 1, p. 75-78, 1993.

A abordagem estrutural das representações sociais. In: MOREIRA, A. S. P.; OLIVEIRA, D. C. (Org.). Estudos interdisciplinares de representação social. Goiânia: AB Editora, 1998. p. 27-38.

AHOLA-LAUNONEN, J. The evolving idea of social responsability in bioethics. Cambridge Quarterly of Healthcare Ethics, Cambridge, v. 24, p. 204-213, 2015.

ALMEIDA, A. M. O.; SANTOS, M. F. S. Representações sociais masculinas de saúde e doença. In: TRINDADE, Z. A.; MENANDRO, M. C. S.; NASCIMENTO, C. R. R. (Org.). Masculinidades e práticas de saúde. Vitória: GM Editora, 2011. p. 99-128.

ALMEIDA-FILHO, N. O que é saúde? Rio de Janeiro: Fiocruz, 2011. 160 p.

. Towards a unified theory of health-disease: I. health as a complex model-object. Revista de Saúde Pública, São Paulo, v. 47, n. 3, p. 433-50, 2013.

BRASIL. Decreto no 7469, de 4 de maio de 2011. Regulamenta a Lei Complementar no 94, de 19 de fevereiro de 1998, que autoriza o Poder Executivo a criar a Região Integrada de Desenvolvimento do Distrito Federal e Entorno - RIDE e instituir o programa especial de desenvolvimento do Entorno do Distrito Federal. Diário Oficial da Uniāo, Brasília, DF, 5 de maio de 2011, p. 4.

BRASIL, E. G. M.; COSTA, E. C.; JORGE, M. S. B. Representações sociais de usuários e trabalhadores de um centro de atenção psicossocial da região Nordeste. Revista Baiana de Saúde Pública, Salvador, v. 36, n. 2, p. 368-385, 2012.

CÂMARA, A. M. C. S. et al. Percepção do processo saúde-doença: significados e valores da educação em saúde. Revista Brasileira de Educação Médica, Rio de Janeiro, v. 36, n. 1, p. 40-50, 2012. Suplemento 1. 
CAMPOLINA, A. G. et al. A transição de saúde e as mudanças na expectativa de vida saudável da população idosa: possíveis impactos da prevenção de doenças crônicas. Caderno de Saúde Pública, Rio de Janeiro, v. 29, n. 6, p. 1217-1229, 2013.

CAMPOS, R. T. O. et al. Avaliação da qualidade do acesso na atenção primária de uma grande cidade brasileira na perspectiva dos usuários. Saúde em Debate, Rio de Janeiro, v. 38, n. especial, p. 252-264, 2014.

CANGUILHEM, G. O normale o patológico (1943). 6. ed. São Paulo: Forense Universitária, 2009. 154 p.

COMPANHIA DE PLANEJAMENTO DO DISTRITO FEDERAL - CODEPLAN. Perfil socioeconômico dos moradores dos municípios da Área Metropolitana de Brasília: PMAD/2013. Brasília: Codeplan, 2013.

DURÁN, P. R. F.; GERSCHMAN, S. Desafios da participação social nos conselhos de saúde. Saúde e Sociedade, São Paulo, v. 23, n. 3, p. 884-896, 2014.

GAZZINELLI, M. F. C. et al. Representações sociais da educação em saúde pelos profissionais da equipe de saúde da família. Trabalho, Educação e Saúde, Rio de Janeiro, n. 11, v. 3, p. 553-571, 2013.

GOMES, A. M. T.; OLIVEIRA, D. C.; SÁ, C. P. O Sistema Único de Saúde na representação social de usuários: uma análise de sua estrutura. Revista Brasileira de Enfermagem, Brasília, v. 64, n. 4, p. 631-8, 2011.

HUBER, M. et al. How should we define health? British Medical Journal, London, n. 343, p. d4163, 2011.

JODELET, D. Encounters between forms of knowledge. Papers on Social Representations, London, v. 22, n. 1, p. 9.1-9.20, 2013.

Problemáticas psicossociais da abordagem da noção de sujeito. Cadernos de Pesquisa, São Paulo, v. 45, n. 156, p. 314-327, 2015.

LAURELL, A. C.; MARQUEZ, M. El desgaste obrero en México: Proceso de produccion y salud. México: Ediciones Era, 1983. 118 p. (Colección Problemas de México).

MENDES, A. C. G. et al. Acessibilidade aos serviços básicos de saúde: um caminho ainda a percorrer. Ciência \& Saúde Coletiva, Rio de Janeiro, v. 17, n. 11, p. 2.903-2.912, 2012.

MINAYO, M. C. S. Qualidade de vida e saúde como valor existencial. Ciência e Saúde Coletiva, Rio de Janeiro, v. 18, n. 7, p. 1868-1868, 2013.

MOSCOVICI, S. Representaçôes Sociais: Investigaçôes em psicologia social. 7. ed. Petrópolis: Vozes, 2010. 408 p.

PAIVA, F. S.; VAN STRALEN, C. J.; COSTA, P. H. A. Participação social e saúde no Brasil: revisão sistemática sobre o tema. Ciência e Saúde Coletiva, Rio de Janeiro, n. 19, v. 2, p. 487-498, 2014. 
PIRES, M. R. G. M. et al. Oferta e demanda por média complexidade/SUS: relação com atenção básica. Ciência e Saúde Coletiva, Rio de Janeiro, sup. 1, n. 15, p. 1009-1019, 2010. SÁ, C. P. Teoria das representações sociais: teoria e pesquisa do núcleo central. Temas em Psicologia, Ribeirão Preto, v. 3, n. 1, p.19-33, 1996.

SAÏAS, T. et al. Prevention in mental health: social representations from french professionals. Health Sociology Review, Australia, v. 23, n. 2, p. 159-164, 2014.

SANTOS, D. S. et al. Processo saúde/doença e estratégia de saúde da família: o olhar do usuário. Revista Latino-Americana de Enfermagem, Ribeirão Preto, v. 22, n. 6, p. 918-925, 2014.

SCHERER-WARREN, I. Das mobilizações às redes de movimentos sociais. Sociedade e Estado, Brasília, v. 21, n. 1, p. 109-130, 2006.

SCHMIDT, M. I. et al. Chronic non-communicable diseases in Brazil: burden and current challenges. The Lancet, London, v. 377, n. 9781, p. 1949-1961, 2011.

SHIMIZU, H. E.; MOURA, L. M. de. As representaçôes sociais do controle social em saúde: os avanços e entraves da participação social institucionalizada. Saúde e Sociedade, São Paulo, v. 24, n. 4, p.1.180-1.192, 2015.

SHIMIZU, H. E. et al. Representações sociais dos conselheiros municipais acerca do controle social em saúde no SUS. Ciência \& Saúde Coletiva, Rio de Janeiro, v. 18, n. 8, p. 2275-2284, 2013.

SHIMIZU, H. E. et al. A estrutura das representações sociais sobre saúde e doença entre membros de movimentos sociais. Ciência \& Saúde Coletiva, Rio de Janeiro, v. 20, n. 9, p. 2899-2910, 2015.

VIEIRA, V. L. et al. Ações de alimentação e nutrição e sua interface com segurança alimentar e nutricional: uma comparação entre Brasil e Portugal. Saúde e Sociedade, São Paulo, v. 22, n. 20, p. 603-617, 2013.

WORLD HEALTH ORGANIZATION - WHO. The Global Burden of Disease: 2004 Update. Geneva: World Health Organization, 2008.

\section{Nota}

${ }^{1}$ L. M. de Moura realizou a coleta, análise e interpretação dos dados; redação do artigo; revisão crítica relevante do conteúdo intelectual; aprovação da versão final a ser publicada. H.E. Shimizu foi responsável pela concepção do projeto; análise e interpretação dos dados; redação do artigo; revisão crítica relevante do conteúdo intelectual; aprovação da versão final a ser publicada. 
Social representations of health and illness of municipal health counselors

The study aimed to know the structure of the social representations of health and illness of the municipal councilors of the Integrated Development Region of the Federal District and Surroundings, as well as to analyze the relationship between these social representations and the role of health advisers in the system. The Theory of Social Representations and the Central Nucleus were adopted as theoretical reference. Seventy one questionnaires were applied to the counselors to verify their profile, in addition to using the technique of free and hierarchical association of words with the terms "health" and "disease", with analysis by EVOC software. Regarding the profile of the directors, 16.9\% are representatives of managers, $40.8 \%$ of employees and $42.3 \%$ of users. The results reveal that the social representation of health is associated to the ideas of care, quality of life and life associated with longevity. The social representation of disease is linked to pathology, objectified in cancer and the idea of pain, sadness, suffering as a result of illness. It is necessary to advance the understanding of the health-disease process, considering it as a historically constructed psychosocial phenomenon, which, due to its comprehensiveness and dynamicity, also requires an analysis from the cultural perspective.

> Keywords: health; disease; social representation; health advice. 